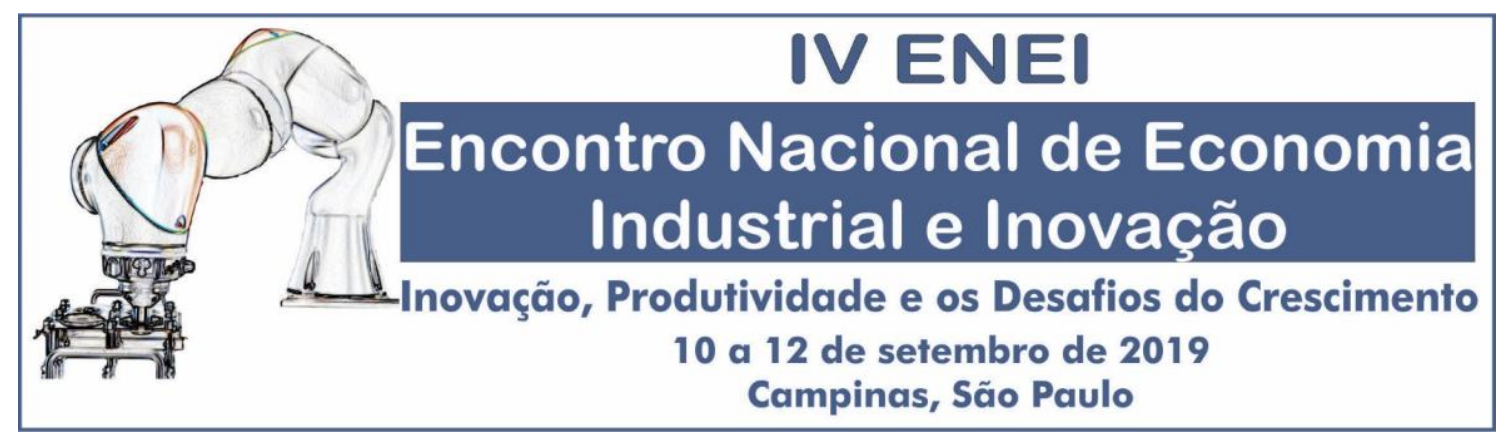

Área temática: Inovação e mudanças técnica, organizacional e institucional (5) Inovação, competências e competitividade (5.7)

\title{
Obstáculos à inovação e porte das empresas industriais no Brasil. Rumo a políticas públicas de incentivo à inovação mais assertivas.
}

\author{
Tulio Chiarini - Instituto Nacional de Tecnologia, INT \\ tulio.chiarini@int.gov.br
}

\section{Vanessa Parreiras Oliveira - Universidade Estadual de Campinas, UNICAMP vparreiras@uol.com.br}

\author{
Márcia Siqueira Rapini - Universidade Federal de Minas Gerais, UFMG \\ msrapini@cedeplar.ufmg.br
}

\begin{abstract}
RESUMO
Nesse artigo é feita uma análise exploratória e descritiva dos obstáculos à inovação nas empresas brasileiras, com o objetivo de encontrar elementos para corroborar a seguinte proposição: os obstáculos econômicos (e institucionais), tecnológicos e organizacionais são fatores que dificultam e impedem processos inovativos tanto em empresas 'inovadoras' e 'não inovadoras', no entanto, o porte da empresa (seja ela inovadora ou não) importa. Isso é, quanto maior o tamanho da empresa (de acordo com o número de empregados) menos obstáculos ela enfrenta para inovar vis-à-vis as médias e micro e pequenas empresas (MPEs). Para a análise proposta são utilizados dados da PINTEC/IBGE, abrangendo os resultados das últimas cinco edições (2003, 2005, 2008, 2011 e 2014).
\end{abstract}

Palavras-chave: Inovação, obstáculos à inovação, porte de empresas, PINTEC.

JEL code: D00; O25; O30; O32

\begin{abstract}
We conduct an exploratory and descriptive analysis of the obstacles to innovation in Brazilian companies and we seek to find elements to corroborate the following proposition: economic (and institutional), technological and organizational obstacles are factors that hinder and impede innovative processes in both 'innovative' and 'non-innovative' companies, however, the size of the company (whether innovative or not) matters. That is, the larger the company (according to the number of employees) the fewer obstacles it faces to innovate vis-à-vis medium and small and micro enterprises (SMEs). For the proposed analysis we use data from Brazilian Innovation Survey from IBGE, covering the last five editions (2003, 2005, 2008, 2011 and 2014).
\end{abstract}

Key-words: Innovation, obstacles to innovation, firm size, PINTEC. 
Há uma crescente preocupação dos formuladores de políticas públicas com os elementos que afetam processos inovativos em empresas. A avaliação dos obstáculos ao seu insucesso possui relevância econômica, uma vez que sua remoção ou mitigação pode ampliar a população de empresas inovadoras e aumentar o desempenho daquelas já existentes (D'este et al., 2012).

A literatura empírica internacional recente com foco em inovação tem devotado crescente atenção à percepção dos obstáculos à inovação e ao seu impacto (desencorajador) sobre as decisões das empresas de se engajarem em atividades inovativas, à intensidade deste engajamento e à propensão a inovar (Pellegrino; Savona, 2013; Coad et al., 2016). Há, todavia, uma escassa discussão no Brasil sobre o papel dos obstáculos à inovação nas empresas industriais de acordo com o seu porte e esse artigo procura ser uma contribuição neste sentido ${ }^{1}$. Desse modo, busca-se identificar e examinar dados empíricos que corroboram a seguinte proposição: os obstáculos econômicos (e institucionais), tecnológicos e organizacionais são fatores que dificultam e impedem processos inovativos tanto em empresas industriais 'inovadoras' e 'não inovadoras', no entanto, o porte da empresa (seja ela inovadora ou não) importa. Isso é, quanto maior o tamanho da empresa menos obstáculos ela enfrenta para inovar vis-à-vis as empresas de menor porte. Isto está de acordo com a literatura econômica a qual afirma que empresas grandes possuem, além de ganhos na escala produtiva, concentração de recursos - financeiros, mas não somente eles - para inovar (Chandler Jr, 1990; Penrose, 2006; Schumpeter, 2008 [1942]).

Para encontrar elementos que sustentem a proposição anterior, são utilizados dados da Pesquisa de Inovação do Instituto Brasileiro de Geografia e Estatística (PINTEC/IBGE), abrangendo os resultados das últimas cinco edições (PINTECs 2003, 2005, 2008, 2011 e 2014). São analisados dados relativos aos problemas e obstáculos à inovação encontrados pelas empresas no desenvolvimento de suas atividades inovativas, levando em conta o seu porte- cuja proxy é o número de empregados: micro e pequenas empresas (MPEs), médias e grandes empresas. As evidências fornecidas pela PINTEC contribuem para a formulação de políticas públicas mais assertivas de acordo com o seu objetivo:

i. incentivar que empresas industriais que não inovam comecem a inovar;

ii. incentivar que empresas industriais que já inovam continuem a fazê-lo.

$\mathrm{O}$ artigo está estruturado da seguinte maneira. $\mathrm{Na}$ seção 2, são apresentados argumentos que mostram a importância do processo inovativo do ponto de vista da teoria econômica evolucionária e também a relevância de se analisar os obstáculos ao processo de inovação. Na seção 3 é apresentada a base de dados. Na seção 4 são apresentados os dados sobre os obstáculos à inovação nas empresas brasileiras por porte, propondo-se uma discussão. Por fim, a seção 5 abarca as considerações finais e proposições que visam auxiliar a formulação de políticas públicas de acordo com o porte e o objetivo da política.

\section{Contribuições teóricas e empíricas}

\subsection{Processo de inovação e seus obstáculos}

$\mathrm{Na}$ teoria evolucionária as empresas são entendidas como organizações que 'aprendem' (Malerba, 1992; Lundvall; Johnson, 1994; Nelson; Winter, 2005 [1982]). Desse modo, o processo de aprendizado é essencial para que elas possam compreender suas estratégias e possam conceber suas trajetórias de aquisição de competências necessárias à geração de processos inovativos capazes de criar assimetrias no processo concorrencial. Esse, por sua vez, é um processo cumulativo, o qual

\footnotetext{
${ }^{1}$ Podemos citar os seguintes trabalhos recentes que tratam sobre a temática no Brasil: Rapini (2013), Kühl e Cunha (2013), Oliveira e Bertoni (2014), Oliveira (2015), Maia e Silva-Filho (2016), Silva-Filho et al. (2017) e Rapini et al. (2017). Podemos ainda citar o Relatório da Fiesp (2010)).
} 
permite a diferenciação entre as empresas e, por conseguinte, o seu desempenho. Estas diferenças resultam de distintas estratégias, as quais gerarão empresas com variadas estruturas e competências, incluindo aquelas relacionadas às atividades inovativas (Nelson, 1991).

A inovação bem-sucedida depende da combinação, por parte das empresas, de uma gama ilimitada de competências (Borrás; Edquist, 2015), incluindo a capacidade para acessar financiamentos, entender as necessidades e demandas da sociedade, contratar mão de obra qualificada e estabelecer interações efetivas com outras organizações.

Assim, a falta de entendimento do mercado, a falta de mão de obra qualificada e a falta de interação com demais organizações são obstáculos ao processo inovativo. No entanto, as barreiras à inovação não se resumem aos obstáculos internos às empresas causados pela falta (ou deficiência) de competências-chave (Conner; Prahalad, 1996). Há barreiras que decorrem do ambiente no qual a empresa está inserida, podendo ser: i) deficiências de mercado (externalidades, assimetria de informações, custos de transações); ii) predomínio (ou ausência) de certas instituições (Acemoglu; Robinson, 2012); iii) características dos Sistemas de Inovação (Lundvall, 1992).

Nesse contexto, é possível classificar as barreiras quanto a sua natureza, sendo elas internas ou externas às empresas (Hadjimanolis, 2003). D'este et al. (2012) notam que as empresas inovadoras são necessariamente compelidas a lidar com muitas barreiras (externas e internas), contudo, algumas são dissuadidas do engajamento de processos inovativos por causa dessas dificuldades e permanecem 'travadas' às rotinas já estabelecidas (chamado efeito lock-in) e acabam por não inovar (são as chamadas empresas 'não inovadoras'). Portanto, as empresas 'não inovadoras' falham em trazer novos produtos ou processos ao mercado devido à incapacidade de superar tais obstáculos com que se deparam durante o processo inovativo.

Dadas à complexidade do processo inovativo e a multiplicidade de interações envolvidas, as barreiras possuem caráter dinâmico e podem afetar distintos estágios do processo inovativo (Hadjimanolis, 2003). Portanto, elas não são pré-existentes à inovação, mas se desenvolvem durante o processo inovativo, adicionando dificuldade a sua avaliação e superação (Hadjimanolis, 2003). As barreiras podem afetar diretamente as empresas, mas também indiretamente, atuando em diferentes organizações intermediárias do processo de inovação, como bancos e concorrentes (Piatier, 1984 apud Hadjimanolis, 2003), ou seja, afetando diferentes atores do Sistema de Inovação. Ademais, distintas barreiras podem agir não de forma isolada, mas de forma complementar, levando a círculos viciosos (Mohnen;Rosa, 2001), podendo impactar negativamente o processo ao provocar desde atrasos na superação das barreiras até mesmo sua completa interrupção (Hadjimanolis, 2003).

Cabe ainda relativizar a 'universalidade' das barreiras à inovação, uma vez que sua natureza, frequência e impacto provavelmente variam de acordo com o contexto ao qual a empresa desempenha suas atividades inovativas. De acordo com Hadjimanolis (2003), há diferentes padrões de constrangimentos em contextos específicos. Tais contextos incluem o tipo de inovação, o tipo de inovador, o tamanho da empresa, o setor ao qual a empresa pertence, sua localização geográfica e provavelmente os ciclos de negócios (Hadjimanolis, 2003). Na próxima subseção, a questão concernente ao porte da empresa será discutido.

No entanto, antes de prosseguir, é preciso reconhecer que a eliminação dos obstáculos ao processo inovativo não necessariamente garante inovações uma vez que inovar é um fenômeno complexo e não-linear (Etzkowitz; Leydesdorff, 2000; Arthur, 2009). A remoção (ou minimização) das barreias é necessária, porém não suficiente para garantir o sucesso das inovações (Hadjimanolis, 2003). Ademais, não se está assumindo aqui que toda e qualquer barreira ao processo inovativo seja algo negativo e que deva ser eliminada. Vale ressaltar que algumas barreiras podem ter efeitos positivos ao estimular processos de aprendizado e experiência para as empresas (Tang; Yeo, 2003).

\subsection{Obstáculos à inovação e porte das empresas}

O tamanho das empresas provavelmente determina não apenas a natureza, mas também a importância das barreiras à inovação e as pequenas empresas são as que percebem seus impactos 
como os mais severos (Hadjimanolis, 2003). Alguns trabalhos abordam os problemas e obstáculos ao desenvolvimento de MPEs e médias empresas. Segundo Zevallos (2003), as condições nas quais estas empresas se desenvolvem na América Latina não lhes são particularmente favoráveis. Isto está em grande parte relacionado às suas competências endógenas (baixo grau de adoção tecnológica, pouca qualificação de seus trabalhadores e/ou do próprio empresário, fragilidade administrativa e baixa produtividade) e também a certas condições do ambiente, que as afetem em maior grau do que às grandes empresas. Molina-Ycaza e Sánchez-Riofrío (2016) acrescentam que os principais obstáculos para o desenvolvimento das MPEs e médias empresas nestes países são o acesso ao financiamento e à tecnologia e a falta de recursos humanos especializados.

Obstáculos que se referem aos limitados recursos tangíveis e intangíveis são apresentados em estudos que analisam os processos inovativos tanto em MPEs quanto em médias empresas (Rothwell, 1989; Freel, 2000; Hewitt-Dundas, 2006; Molina-Ycaza; Sánchez-Riofrío, 2016). Segundo Hewitt-Dundas (2006), por exemplo, a probabilidade das pequenas e grandes plantas empreenderem inovação é fortemente influenciada pelos seus constrangimentos de recursos e pelas capacidades herdados de um período para o seguinte. Todavia, a falta de recursos financeiros, as limitadas oportunidades de mercado e as pressões legislativas ou regulatórias são mais significativas para as pequenas plantas.

Freel (2000) argumenta que pequenas empresas enfrentam restrições relacionadas à ausência de trabalho tecnicamente qualificado; ao uso restrito de informação e competências externas; dificuldade em atrair/manter financiamentos e falta de capacidade relacionada para disseminar o risco; inadequação da gestão original para além da prescrição inicial; e custos imódicos da conformidade regulatória. Conforme o autor, as limitações ao processo inovativo em pequenas empresas podem ser divididos em quatro conjuntos de componentes principais: a) financeiros; b) gestão e marketing; c) mão de obra qualificada; e d) informação.

É interessante notar que são escassos os trabalhos que abordam os obstáculos à inovação de micro, pequenas e médias empresas com base nos surveys de inovação. Oliveira e Bertoni (2014) encontram que, dentre as razões apontadas pelas pequenas e médias empresas brasileiras para não inovar nas edições de 2008 e 2011 da PINTEC/IBGE, a principal refere-se às "condições de mercado", que levam em conta as imperfeições de demanda e/ou da estrutura de oferta. Demais motivos impeditivos à inovação também foram apresentados, porém, por um menor número de pequenas e médias empresas: os elevados custos da inovação, os riscos econômicos excessivos, a falta de pessoal qualificado, a escassez de fontes apropriadas de financiamento, dentre outros. Uma vez já inovando, os obstáculos concernentes aos problemas internos à empresa, deficiências técnicas, problemas de informação e estrutura organizacional tornam-se mais significativos para as pequenas e médias empresas brasileiras.

No que tange à importância e à relevância dos constrangimentos financeiros, tem-se que o acesso aos recursos financeiros e os supostos déficits de capital são as mais comumente citadas e debatidas 'barreiras à inovação' na literatura que aborda as pequenas empresas (Freel, 2000). O problema do acesso ao capital deriva de falhas nos mercados de capitais, como o escasso financiamento ao capital de risco, os procedimentos excessivos, as altas taxas e os prazos restritivos (Zevallos, 2003). O racionamento do crédito por parte das instituições financeiras ocasiona um limitado crescimento da micro, pequena e média empresa e, em certos casos, pode significar o encerramento de suas operações (Molina-Ycaza e Sánchez-Riofrío (2016). A dificuldade de seu acesso se deve principalmente às elevadas garantias, às altas taxas de juros, aos requisitos excessivos, ao custo e tempo envolvidos nos procedimentos e ao uso do autofinanciamento.

Canepa e Stoneman (2008) identificam que as pequenas empresas podem ser mais fortemente constrangidas por causa da disponibilidade de fundos gerados internamente. Assim, o financiamento de um projeto de inovação de um dado tamanho pode ser mais limitado para essas empresas do que para aquelas de grande porte, levando-as frequentemente a se aproximarem de financiadores externos. Entretanto, os problemas de assimetria de informação e do escopo para o risco moral podem ser mais severos para este conjunto de empresas do que para as empresas de grande porte, resultando em racionamento de crédito geral ou falha de mercado na provisão de 
recursos financeiros para as pequenas empresas (Freel, 2000; Hewitt-Dundas, 2006; Canepa; Stoneman, 2008).

Molina-Ycaza e Sánchez-Riofrío (2016) observam que a falta de financiamento limita as tentativas de melhora a favor do desenvolvimento das competências laborais de micro, pequenas e médias empresas. Da mesma forma, as limitadas capacidades dos trabalhadores reduzem as possibilidades de absorver novos conhecimentos (associados às novas tecnologias). Conforme os autores, a qualificação dos recursos humanos na micro, pequena e média empresa constitui um problema declarado tanto na União Europeia como na América Latina.

Bosworth (1989) salienta que há ligações diretas entre a intensidade de capital, o nível de tecnologia e a estrutura de habilidades (skills) da empresa. Com o objetivo de desenvolver e crescer, empresas menores enfrentam o problema de aumentar a qualidade e o nível de expertise de sua força de trabalho. Caso contrário, a empresa fica vulnerável frente à mudança nas condições de mercado e aos avanços tecnológicos entre os maiores concorrentes. Entretanto, as pequenas empresas são menos capazes de atrair pessoal de elevada-qualidade, ademais de haver uma tendência para que o gestor-proprietário do pequeno negócio subestime a qualidade de sua mão-deobra.

\section{Metodologia}

O governo brasileiro seguiu a tendência internacional de pesquisas de inovação e influenciado tanto pelo Manual de Frascati (1981) quanto pelo Manual de Oslo (1992) desenvolveu, através do IBGE, a Pesquisa de Inovação (PINTEC) com a primeira edição no ano $2000^{2}$. A metodologia sugerida pela segunda edição do Manual de Oslo foi adotada pela PINTEC, notadamente aquela proposta na terceira versão do Community Innovation Survey (CIS-3) (Bastos et al., 2003).

A PINTEC é o principal Survey sobre as atividades inovativas das empresas brasileiras (por setor de atividade econômica) e é fonte de informação para cálculo de diversos indicadores sobre o desempenho inovativo (indicadores de resultados, i.e., output indicators) e sobre os esforços para empreender atividades inovativas (indicadores de esforço, i.e., input indicators). A partir do Survey da PINTEC é possível apontar os impactos relacionados ao produto (melhorar a qualidade ou ampliar a gama de produtos ofertados), ao mercado (manter ou ampliar a participação da empresa no mercado, abrir novos mercados), ao processo (aumentar a flexibilidade ou a capacidade produtiva, reduzir custos), aos aspectos relacionados ao meio ambiente, à saúde e segurança, e ao enquadramento em regulamentações e normas. Para ilustrar a riqueza de informações disponíveis a partir da PINTEC, Cavalcante e De Negri (2011), por exemplo, apresentam os principais indicadores de inovação no Brasil.

\subsection{Base de dados Estratégia de coleta dos dados}

Neste artigo foram utilizados dados da Pesquisa de Inovação do Instituto Brasileiro de Geografia e Estatística (PINTEC/IBGE), abrangendo os resultados das últimas cinco edições (PINTECs 2003, 2005, 2008, 2011 e 2014). Vale salientar que não serão analisadas nesse trabalho as respostas da PINTEC realizada em 2000, visto que, por se tratar da primeira pesquisa, contou com o processo de aprendizado das empresas nas suas respostas. De acordo com Rebouças (2005), as empresas passaram a ser mais criteriosas nas respostas após 2000 refletindo em reduções consideráveis em alguns indicadores, que não necessariamente indicam uma queda real. Isto aconteceu nas variáveis analisadas no presente trabalho, por isso optou-se em utilizar os dados do Survey de 2003 em diante até sua última edição disponível.

$\mathrm{O}$ acesso às bases da PINTEC permite separar as empresas industriais (extrativistas e de transformação) em dois conjuntos: empresas que realizaram processos inovativos e aquelas que não os empreenderam. As primeiras são conhecidas como ‘empresas industriais inovadoras' enquanto

\footnotetext{
${ }^{2}$ Silva e Furtado (2017) fazem uma análise, por meio de entrevistas com uma amostra intencional de atores-chave, da gênese da PINTEC, mostrando quais foram as motivações para a sua realização.
} 
que as últimas como 'empresas industriais não inovadoras' ${ }^{3}$. É exatamente esse o primeiro passo para a construção da base de dados a ser analisada nesse artigo.

O grupo de empresas 'não inovadoras' é muito superior ao das inovadoras, conforme pode ser observado a partir da Tabela 1. Para fins de exemplificação, tem-se que em 2014 o total de empresas industriais avaliadas na PINTEC foi superior a 117 mil empresas, das quais pouco mais de 71 mil não implementaram inovações, ou seja, aproximadamente $60 \%$ das empresas respondentes da PINTEC.

Tabela 1 - Universo das empresas industriais, por porte de acordo com faixa de pessoal ocupado na PINTEC, 20032014.

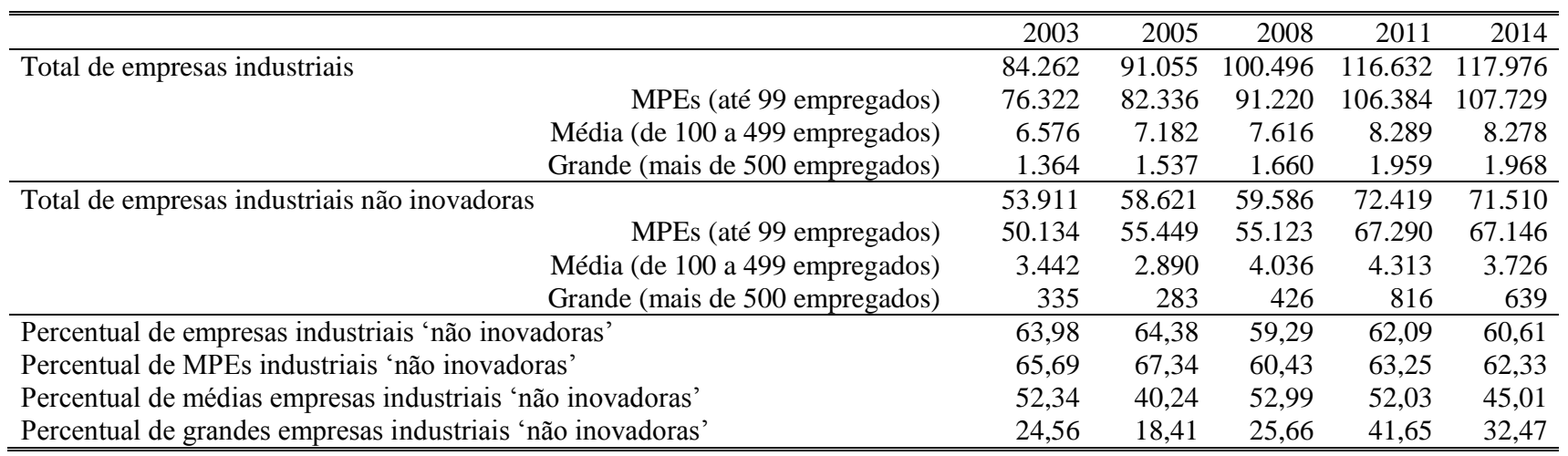

Fonte: Elaboração própria a partir dos dados da PINTEC/IBGE.

O passo seguinte para construção da base de dados é classificar as empresas de acordo com seu porte nos distintos grupos 'empresas industriais inovadoras' e 'empresas industriais não inovadoras'. Vale lembrar que não existe uma única maneira possível de classificar as empresas de acordo com seu tamanho. Várias proxies podem ser utilizadas para a classificação das empresas nas categorias micro, pequena, média e grande. Geralmente utiliza-se da receita bruta anual das empresas ou do número de empregados. Assim mesmo é possível encontrar diferentes classificações, já que os limites que separam uma categoria da outra podem variar. Por exemplo, de acordo com dispositivo legal de 2006 (Lei Complementar n.123), microempresa é aquela que aufere, em cada ano-calendário, receita bruta igual ou inferior a $\mathrm{R} \$ 360$ mil enquanto a empresa de pequeno porte aufere receita bruta superior a $\mathrm{R} \$ 360 \mathrm{mil}$ e igual ou inferior a $\mathrm{R} \$ 4.800$ mil (Brasil, 2006). Acima desse valor, não há definição legal que trate da diferença entre média e grande empresa.

Já de acordo com o IBGE (2012), são consideradas microempresas aquelas com até 9 pessoas ocupadas; empresas pequenas são as que possuem de 10 a 49 pessoas; empresas médias possuem de 50 a 249 pessoas; e as empresas grandes contém 250 ou mais pessoas ocupadas. No entanto, de acordo com o SEBRAE (2013), há uma separação entre setores econômicos distintos (indústria versus comércio e serviços) na classificação das empresas pelo porte. Assim sendo, uma microempresa industrial possui até 19 empregados, uma pequena empresa de 20 a 99, uma média empresa de 100 a 499 e uma grande empresa acima de 500 empregados (SEBRAE, 2013). Nesse artigo, utiliza-se a classificação proposta pelo SEBRAE (2013) e optou-se em somar as micro e pequenas empresas em uma única categoria (MPEs). Desse modo, tem-se os seguintes portes possíveis, por faixa de pessoal ocupado:

i. $\quad$ micro e pequenas empresas - MPEs (até 99 empregados);

ii. média empresas (de 100 a 499); e

iii. grande (mais de 500 empregados).

\footnotetext{
${ }^{3}$ De acordo com a PINTEC inovar significa criar (ou aprimorar) produtos e/ou processos novos (para a empresa, não sendo, necessariamente, novo para o mercado de atuação). Ademais considera-se ainda inovar a implementação de um novo método organizacional nas práticas de negócios da empresa.
} 
Os dados da Tabela 1 apresentam os quantitativos das empresas industriais que responderam ao Survey de Inovação em cada ano por faixa de pessoal ocupado. Pode-se notar que em todos os anos da PINTEC, as MPEs representam mais de $90 \%$ das empresas que participaram da pesquisa, em 2014, por exemplo, das mais de 117 mil empresas, pouco mais de $91 \%$ são empresas industriais com até 99 empregados ocupados.

Tendo sido definidos os grupos de empresas industriais 'inovadoras' e 'não inovadoras' e tendo classificado dentro de cada um desses grupos as empresas por porte, passa-se ao terceiro passo para a construção da base de dados. É possível avaliar quais foram os fatores impeditivos que as empresas industriais não inovadoras tiveram para não terem inovado e quais foram as dificuldades que as empresas industriais inovadoras enfrentaram durante o processo inovativo.

Ao separar as empresas industriais inovadoras das 'não inovadoras', o Survey de Inovação consegue captar a percepção do que dificultou a inovação do primeiro grupo de empresas e a percepção do que impediu as inovações do segundo grupo, conforme apresentado pela Figura 1.

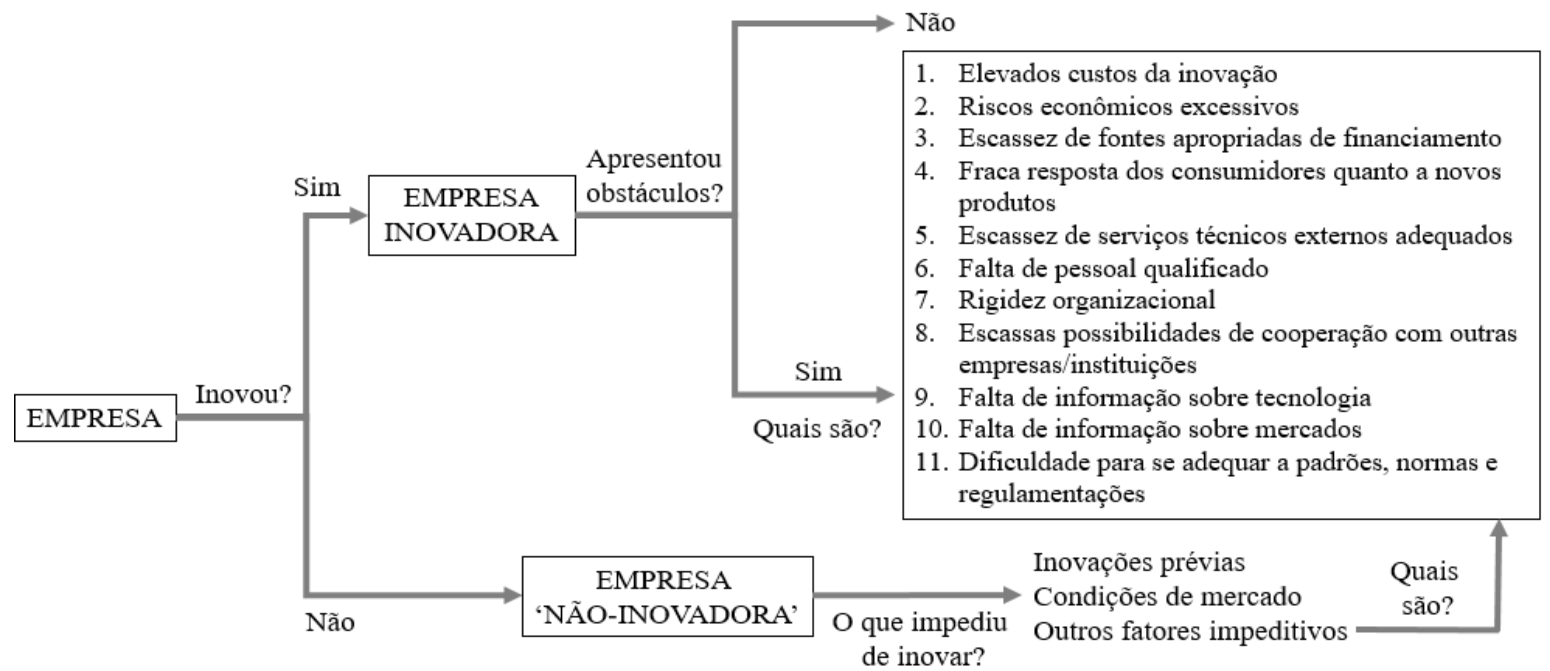

Figura 1 - Fluxograma baseado no Survey de Inovação.

Fonte: Elaboração própria baseada no questionário da PINTEC/IBGE, edição de 2014.

Os obstáculos apresentados pela PINTEC foram agrupados em categorias para fins de simplificação analítica, conforme apresentados na Tabela 2:

i. obstáculos econômicos e institucionais;

ii. obstáculos organizacionais; e

iii. os obstáculos técnicos e tecnológicos.

Tabela 2 - Outros fatores impeditivos ao processo de inovação.

\begin{tabular}{ll|c}
\hline \hline 1. & elevados custos de inovação & \\
2. & riscos econômicos excessivos & Obstáculos econômicos \\
3. & escassez de fontes apropriadas de financiamento & institucionais \\
4. & fraca resposta dos consumidores quanto a novos produtos & \\
5. & escassez de serviços técnicos externos adequados & Obstáculos \\
\hline 6. & falta de pessoal qualificado & Organizacionais \\
7. & rigidez organizacional & Obstáculos informacionais \\
8. & escassas possibilidades de cooperação com outras empresas/instituições & e tecnológicos \\
\hline 9. & falta de informação sobre tecnologia & falta de informação sobre mercados \\
11. & dificuldade para se adequar a padrões, normas e regulamentações & \\
\hline \hline
\end{tabular}

Fonte: Elaboração própria baseada na PINTEC/IBGE. 
Por fim, cabe destacar que as empresas respondentes da PINTEC podem atribuir diferentes graus de importância a cada fator que afeta o processo inovativo, variando de 'baixo', 'médio' e 'alto'. Optou-se nesse trabalho por analisar somente as respostas de grau de importância 'alto', na busca de inferir os obstáculos realmente relevantes para as empresas.

\subsection{Análise dos dados}

Uma vez construída a base de dados das empresas industriais (inovadoras ou não), por porte e que atribuíram grau de importância ‘alto' aos obstáculos à inovação, passa-se a estratégia de análise dos dados.

Optou-se, portanto, em realizar uma análise estatística descritiva, possibilitando organizar, resumir e descrever os aspectos importantes do conjunto de características observadas (REIS; REIS, 2002) e permitindo, portanto, que se tenha uma visão global das suas variações, comparando dois conjuntos (empresas inovadoras e não inovadoras) e comparando seus subconjuntos (MPEs, médias e grandes empresas).

Desse modo, os dados são organizados por meio de tabelas, figuras e também medidas de síntese (como porcentagens) as quais apresentam elementos para corroborar a proposição inicial do artigo. No entanto, vale ressaltar que ao se condensar os dados, perde-se informação (REIS; REIS, 2002), já que não se tem as observações de cada empresa individual e infelizmente não é possível fazer análises sobre relações causais entre tamanho das empresas e obstáculos à inovação devido à falta de acesso aos microdados, impossibilitando análises econométricas.

Na próxima seção são analisados quais os fatores percebidos pelas empresas industriais 'não inovadoras', divididas por porte, que impediram a implementação de inovações em cada período. São também analisados os fatores percebidos pelas empresas industriais inovadoras, por porte, das dificuldades em implementar inovações no Brasil.

\section{$4 \quad$ Problemas e obstáculos à inovação no Brasil}

\subsection{Empresas industriais 'não inovadoras': por que não inovam?}

A PINTEC indica três razões pelas quais as empresas industriais 'não inovadoras' não desenvolveram e nem implementaram inovações, conforme foi representado na Figura 1:

i. Inovações prévias;

ii. Condições de mercado;

iii. Outros fatores impeditivos.

Rapini (2013) havia identificado, com base dos dados da PINTEC, que, dentre os motivos atribuídos pelas empresas 'não inovadoras' que desestimularam a inovação, o principal é as 'condições do mercado'. Sua análise cobriu os dados de 2000 a 2005. Em uma perspectiva de tempo maior, levando em conta os dados de 2003 a 2014, tem-se que o principal obstáculo para as empresas industriais 'não inovadoras' continua sendo as 'condições de mercado' (Rapini, 2013; Rapini et al., 2017).

Do ponto de vista econômico, condições (desfavoráveis) de mercado são geradas por uma deficiência de demanda (seja ela agregada e/ou setorial) ou por uma deficiência da estrutura de oferta (concorrencial ou capacidade instalada) que podem desestimular a inovação (Rapini et al., 2017). Em 2003, das pouco mais de 84 mil empresas industriais que responderam à PINTEC, 63,98\% não desenvolveram nem implementaram inovações. Dessas, 65,39\% apontaram como a principal razão para não terem inovado as 'condições de mercado desfavoráveis'. Já em 2014, das 117.976 empresas industriais presentes na PINTEC, 60,61\% são empresas 'não inovadoras', sendo que 56,03\% delas não desenvolveram e nem implementaram inovações devido às 'condições de mercado' (Figura 2 e Tabela 3, anexo). 


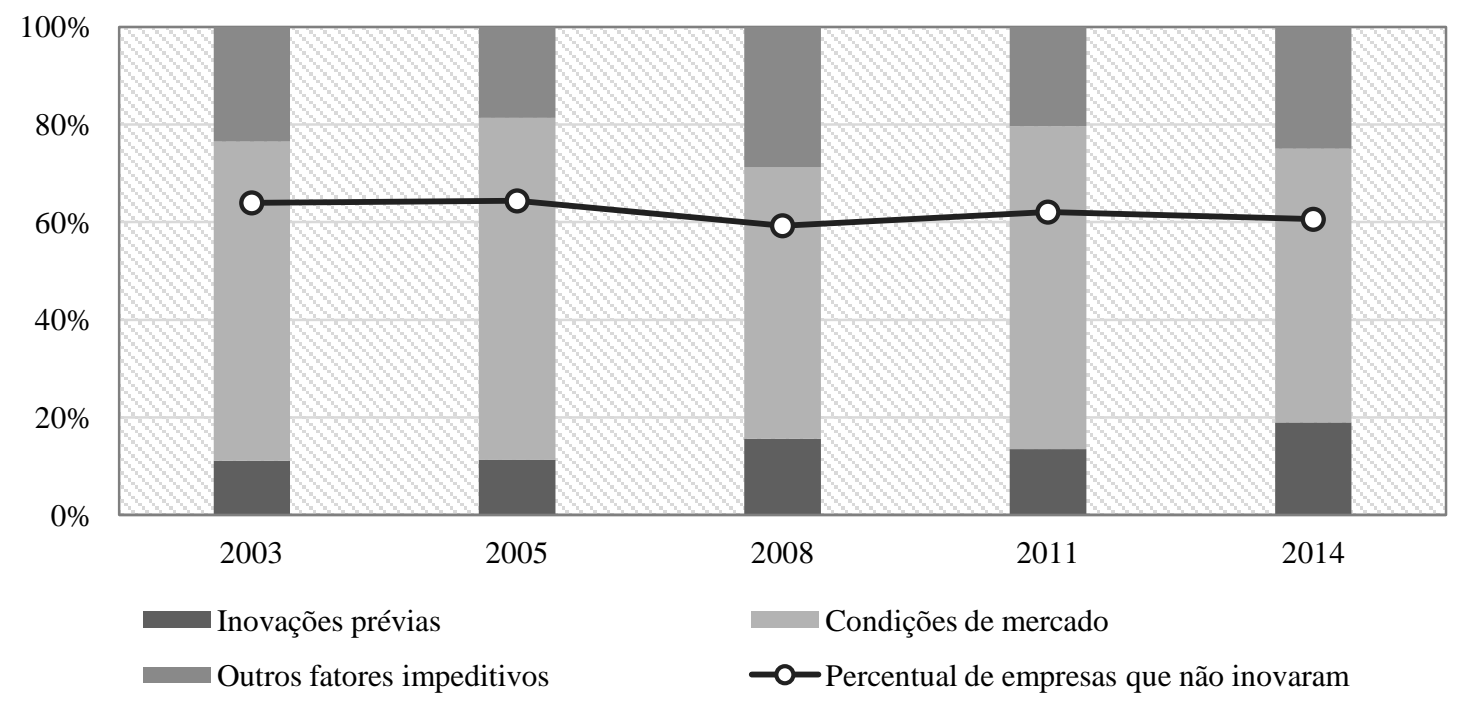

Figura 2 - Empresas industriais que não desenvolveram e nem implementaram inovações, de acordo com os motivos (\%), e percentual de empresas que não implementaram inovações e sem projetos 2003, 2005, 2008, 2011 e 2014 , Brasil.

Fonte: Elaboração própria a partir dos dados da PINTEC/IBGE.

Cabe destacar que o porte das empresas industriais - MPEs, médias e empresas grandes parece não afetar a percepção de que as 'condições de mercado' são obstáculos predominantes. Para todos os portes de empresa as 'condições de mercado' em termos percentuais, foram superior ou bastante próxima a 50\%, apresentando relativa redução na última pesquisa (2014) para todos os portes de empresas industriais 'não inovadoras' (Tabela 3).

Tabela 3 - Distribuição percentual das razões porque as empresas não implementaram inovações, segundo tamanho e total de empresas que não inovaram, 2003, 2005, 2008, 2011 e 2014.

\begin{tabular}{|c|c|c|c|c|c|c|}
\hline & $\%$ & 2003 & 2005 & 2008 & 2011 & 2014 \\
\hline \multirow{3}{*}{$\begin{array}{l}\text { MPEs } \\
\text { (até } 99 \text { empregados) }\end{array}$} & Inovações prévias & 10,69 & 10,91 & 15,29 & 13,02 & 18,58 \\
\hline & Condições de mercado & 65,34 & 70,44 & 55,37 & 66,66 & 56,50 \\
\hline & Outros fatores & 23,98 & 18,65 & 29,34 & 20,31 & 24,92 \\
\hline \multirow{3}{*}{$\begin{array}{l}\text { Empresas industriais médias } \\
\text { (de } 100 \text { a } 499 \text { empregados) }\end{array}$} & Inovações prévias & 15,84 & 17,66 & 19,90 & 19,62 & 24,68 \\
\hline & Condições de mercado & 66,87 & 64,14 & 58,63 & 59,93 & 49,22 \\
\hline & Outros fatores & 17,29 & 18,20 & 21,47 & 20,45 & 26,10 \\
\hline \multirow{3}{*}{$\begin{array}{l}\text { Empresas industriais grandes } \\
\text { (acima de } 500 \text { empregados) }\end{array}$} & Inovações prévias & 24,35 & 20,37 & 22,48 & 23,40 & 26,75 \\
\hline & Condições de mercado & 58,45 & 60,11 & 56,28 & 56,61 & 46,65 \\
\hline & Outros fatores & 17,20 & 19,52 & 21,24 & 19,99 & 26,61 \\
\hline \multirow{4}{*}{$\begin{array}{c}\text { Total de empresas industriais } \\
\text { 'não inovadoras' } \\
\text { (valores absolutos) }\end{array}$} & PMEs & 50.134 & 55.449 & 55.123 & 67.290 & 67,146 \\
\hline & Média & 3.442 & 2.890 & 4.036 & 4.313 & 3,726 \\
\hline & Grande & 335 & 283 & 426 & 816 & 639 \\
\hline & Total (valor absoluto) & 53.911 & 58.621 & 59.586 & 72.419 & 71.510 \\
\hline \multicolumn{2}{|c|}{$\begin{array}{l}\text { Total de empresas industriais que responderam à PINTEC } \\
\text { (valor absoluto) }\end{array}$} & 84.262 & 91.055 & 100.496 & 116.632 & 117.976 \\
\hline
\end{tabular}

Fonte: Elaboração própria a partir dos dados da PINTEC/IBGE.

Apesar de as 'condições de mercado' serem o principal fator apontado pelas 'não inovadoras', há outros que a PINTEC capta: 'inovações prévia' e 'outros fatores'. Esses últimos são apresentados também na Tabela 3 e na Tabela 4 são apresentados os percentuais das empresas 'não inovadoras' que atribuíram grau de importância 'alta' a 'outros fatores' limitadores do processo inovativo. 
Tabela 4 - Distribuição percentual dos obstáculos de grau de importância 'alto' apontados pelas empresas industriais 'não inovadoras' que impedem o processo inovativo 2003, 2005, 2008, 2011 e 2014.

\begin{tabular}{|c|c|c|c|c|c|c|}
\hline \multirow{2}{*}{$\begin{array}{l}\text { Tipos de } \\
\text { obstáculos }\end{array}$} & \multirow{2}{*}{ Obstáculos } & \multicolumn{5}{|c|}{ Empresas industriais 'não inovadoras' } \\
\hline & & 2003 & 2005 & 2008 & 2011 & 2014 \\
\hline \multirow{5}{*}{$\begin{array}{l}\text { Econômicos e } \\
\text { institucionais }\end{array}$} & 1. Elevados custos da inovação & 71,04 & 66,86 & 58,08 & 56,13 & 58,50 \\
\hline & 2. Riscos econômicos excessivos & 58,39 & 51,34 & 49,19 & 43,59 & 50,39 \\
\hline & $\begin{array}{l}\text { 3. Escassez de fontes apropriadas de } \\
\text { financiamento }\end{array}$ & 45,68 & 50,76 & 39,69 & 38,23 & 41,85 \\
\hline & $\begin{array}{l}\text { 4. Fraca resposta dos consumidores quanto a } \\
\text { novos produtos }\end{array}$ & 7,89 & 6,96 & 10,00 & 10,17 & 18,16 \\
\hline & $\begin{array}{l}\text { 5. Escassez de serviços técnicos externos } \\
\text { adequados }\end{array}$ & 8,09 & 12,53 & 10,64 & 18,72 & 19,10 \\
\hline \multirow{3}{*}{ Organizacionais } & 6. Falta de pessoal qualificado & 18,66 & 15,50 & 19,55 & 40,71 & 30,53 \\
\hline & 7. Rigidez organizacional & 6,40 & 6,32 & 6,67 & 13,39 & 21,76 \\
\hline & $\begin{array}{l}\text { 8. Escassas possibilidades de cooperação com } \\
\text { outras empresas/instituições }\end{array}$ & 11,85 & 14,14 & 17,56 & 12,63 & 20,11 \\
\hline \multirow{3}{*}{$\begin{array}{l}\text { Técnicos e } \\
\text { tecnológicos }\end{array}$} & 9. Falta de informação sobre tecnologia & 8,86 & 10,94 & 8,62 & 13,47 & 16,88 \\
\hline & 10. Falta de informação sobre mercados & 8,01 & 7,43 & 6,69 & 10,14 & 12,42 \\
\hline & $\begin{array}{l}\text { 11. Dificuldade para se adequar a padrões, normas } \\
\text { e regulamentações }\end{array}$ & 15,56 & 15,65 & 12,93 & 15,77 & 22,77 \\
\hline
\end{tabular}

Fonte: Elaboração própria a partir dos dados da PINTEC/IBGE.

\subsection{1 'Outros fatores': obstáculos econômicos e institucionais}

Para as empresas 'não inovadoras', dentre os 'outros fatores impeditivos' ao processo de inovação, os obstáculos econômicos e institucionais são os mais citados. O principal deles são os 'elevados custos envolvidos nos processos inovativos', os quais, por exemplo, relacionam-se aos gastos diretos com atividades de $\mathrm{P} \& \mathrm{D}$, com mão de obra altamente qualificada, com os custos circunscritos ao risco técnico/tecnológico, e a inserção da inovação no mercado (risco comercial).

Por exemplo, em 2003, 71,04\% das empresas que não inovaram atribuíram 'alto' grau de importância para os 'elevados custos da inovação'. Cabe destacar que existe um movimento no sentido de reduzir a importância dos 'elevados custos da inovação' como fator impeditivo das empresas industriais que não inovaram (Tabela 4). Em 2014, das mais de 71 mil empresas 'não inovadoras', 17.875 deram algum grau de importância aos obstáculos à inovação (taxa de resposta de 25,00\%), das quais 50,39\% atribuíram grau de importância 'alto' para os 'elevados custos da inovação'. A relativa redução de importância desse obstáculo ocorre tanto para MPEs quanto para médias empresas, as quais passaram a dar menos importância aos 'elevados custos da inovação' como obstáculo ao processo inovativo, no entanto, para grandes empresas 'não inovadoras' isso não ocorre (de 43,69\% em 2003 aumenta para 57,81\% em 2014).

Já os 'riscos econômicos excessivos' são apresentados como o segundo obstáculo mais importante para as empresas industriais 'não inovadoras' (independente do porte, ver Tabela 6, no anexo). Cabe destacar, no entanto, que apenas para o grupo de grandes empresas 'não inovadoras', em 2014, os 'riscos econômicos excessivos' ultrapassam em importância os 'elevados custos de inovação', passando a ser percebidos como o principal obstáculo (Figura 3 e Tabela 6, no anexo).

As empresas industriais 'não inovadoras' também apontaram a 'escassez de fontes apropriadas de financiamento' como fator que impede os processos inovativos. Em 2003, 45,68\% delas mencionaram ser este um obstáculo de grau de importância 'alta', ao passo que em 2014 passaram a representar 41,85\% (Tabela 4). No entanto, ao se analisar os dados de acordo com o tamanho da empresa, pode-se notar que a escassez de fontes apropriadas de financiamento tem peso maior para as MPEs 'não inovadoras' vis-à-vis às médias e grandes empresas. Enquanto em 2014, 42,08\% das MPEs 'não inovadoras' apontaram como obstáculo de grau de importância 'alto' a escassez de financiamento, no mesmo período, 38,19\% e 40,39\% das empresas médias e grandes deram o mesmo grau de importância.

Os outros dois fatores relacionados aos obstáculos econômicos e institucionais são: 'fraca resposta dos consumidores quanto a novos produtos' e 'escassez de serviços técnicos externos adequados'. Ambos os obstáculos são apontados de forma crescente de 2003 a 2014 pelas empresas 
industriais 'não inovadoras' (Tabela 4). Entretanto, tanto a 'fraca resposta dos consumidores em relação a novos produtos' quanto a 'escassez de serviços técnicos externos adequados' são afetados pelo tamanho da empresa: as empresas mais sensíveis são as MPEs e as médias empresas 'não inovadoras' (Figura 3 e Tabela 6, anexo).

\subsection{2 'Outros fatores': obstáculos organizacionais}

A falta de pessoal qualificado é um importante impeditivo para processos inovativos conforme apresento por Rapini et al. (2017). Para os autores, a percepção das empresas brasileiras sobre a falta de indivíduos qualificados para o processo de inovação é um elemento novo, verificado exatamente no momento em que o aumentaram substancialmente o suporte ao processo de inovação através de políticas de inovação no país, desde 2004.

De fato, no caso das empresas industriais 'não inovadoras', em 2003, 18,66\% informaram que a falta de pessoal qualificado é um obstáculo de grau de importância 'alta', enquanto que em 2014 passaram a representar 30,53\% (Tabela 4). Entretanto, a MPEs 'não inovadoras' são as que mais deram importância em termos percentuais à falta de pessoal qualificado em relação às médias e grandes empresas. Das MPEs, 30,48\% apontaram-na como elemento impeditivo do processo inovativo, enquanto as médias 17,13\% e as grandes 13,40\%, em 2014 (Figura 3 e Tabela 6, anexo).

Os demais obstáculos organizacionais apresentados pelas empresas 'não inovadoras' ('rigidez organizacional' e as 'escassas possibilidades de cooperação com outras empresas/instituições') tiveram percepção crescente como fatores impeditivos à inovação. Vale destacar que a 'rigidez organizacional' afeta de forma diferenciada as empresas de acordo com seu porte: 22,54\% das MPEs 'não inovadoras' apontam-na como relevante, enquanto apenas 11,31\% das médias e 5,15\% das grandes empresas apontaram o mesmo. Igualmente, as 'escassas possibilidades de cooperação' são relativamente mais importantes para as MPEs do que para as médias e grandes empresas 'não inovadoras' (Figura 3 e Tabela 6, anexo).

\subsection{3 'Outros fatores': obstáculos técnicos e tecnológicos}

Dentre os obstáculos técnicos que impedem o processo inovativo, as empresas industriais 'não inovadoras' apresentam a 'dificuldade para se adequar a padrões, normas e regulamentações' como o mais importante $(22,77 \%$ delas em 2014$)$ seguida da 'falta de informação sobre tecnologias' $(16,88 \%)$ e 'falta de informação sobre mercados' $(12,42 \%)$ (Tabela 4).

Ao analisar as empresas 'não inovadoras' por porte, verifica-se que a 'dificuldade para se adequar a padrões, normas e regulamentações' é um fator impeditivo ao processo inovativo menos importante para médias e grandes empresas em comparação com as MPEs. O mesmo pode ser dito sobre os demais obstáculos técnicos e tecnológicos (Figura 3 e Tabela 6, anexo). As MPEs possuem mais 'dificuldades para acessar as informações sobre as tecnologias disponíveis' e sobre os mercados do que as médias e grandes empresas. 


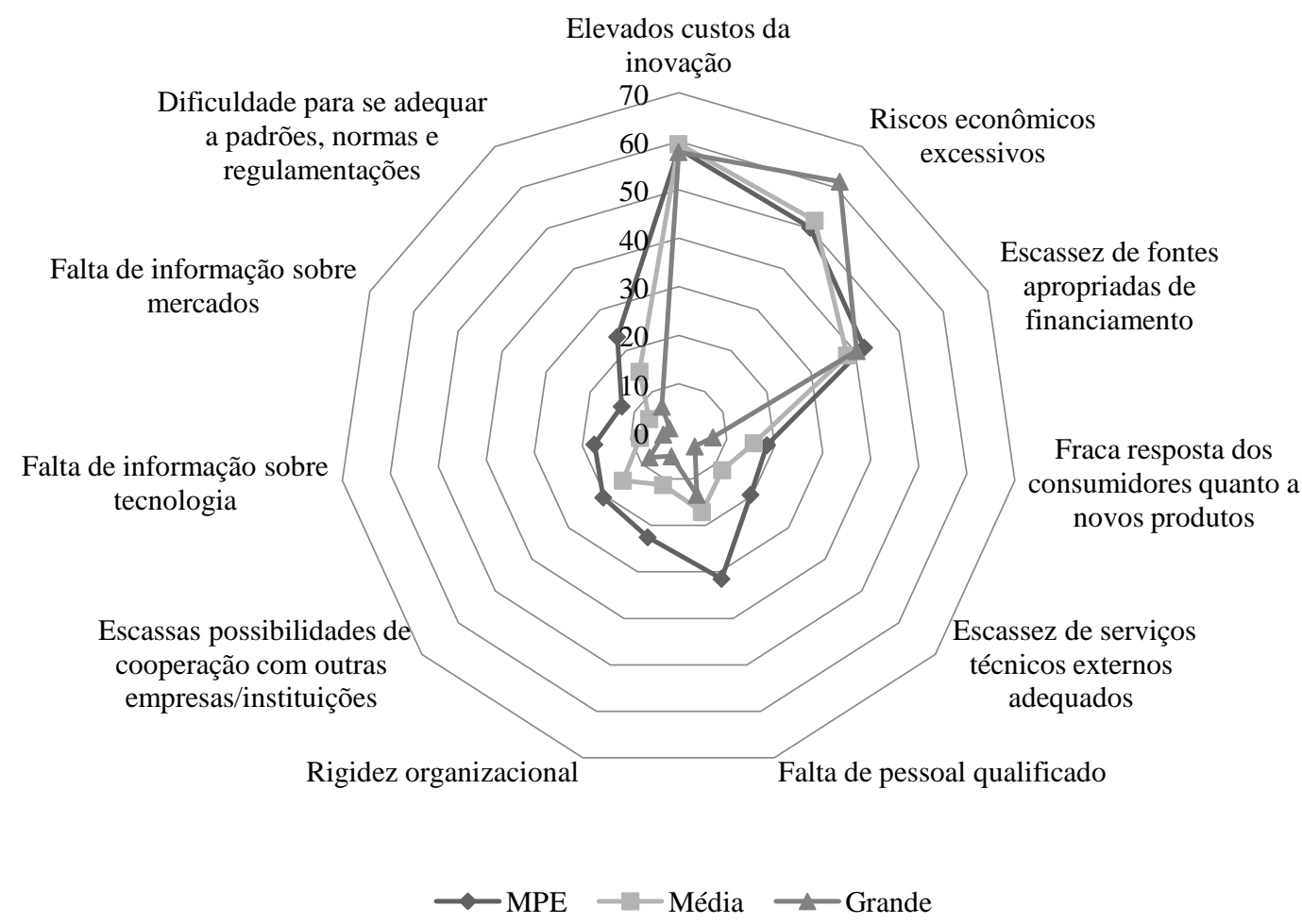

Figura 3 - Percentual do grau de importância 'alta' por obstáculos apontados pelas empresas industriais 'não inovadoras' por porte, 2014.

Fonte: Elaboração própria a partir dos dados da PINTEC/IBGE.

\subsection{Empresas industriais inovadoras: o que dificulta o processo inovativo?}

No que se referem às empresas industriais 'inovadoras', a PINTEC capta os principais fatores que dificultam o seu processo inovativo. Esses estão presentes na Tabela 2 (ver anexo) e são os mesmos fatores que as empresas 'não inovadoras' destacam como 'outros fatores impeditivos'. Na Tabela 5 são expressos os percentuais das empresas industriais 'inovadoras' que atribuíram a esses fatores impeditivos importância 'alta'.

Tabela 5 - Distribuição percentual dos obstáculos de grau de importância 'alto' apontados pelas empresas industriais ‘inovadoras’ que impedem o processo inovativo 2003, 2005, 2008, 2011 e 2014.

\begin{tabular}{|c|c|c|c|c|c|c|}
\hline Tipos de obstáculos & Obstáculos & \multicolumn{5}{|c|}{ Empresas industriais 'inovadoras' } \\
\hline & & 2003 & 2005 & 2008 & 2011 & 2014 \\
\hline \multirow{5}{*}{$\begin{array}{l}\text { Econômico e } \\
\text { institucional }\end{array}$} & 1. Elevados custos da inovação & 54,90 & 54,91 & 47,30 & 51,68 & 52,77 \\
\hline & 2. Riscos econômicos excessivos & 52,84 & 49,04 & 39,28 & 41,50 & 53,36 \\
\hline & 3. Escassez de fontes apropriadas de financiamento & 45,99 & 46,71 & 38,26 & 42,06 & 46,52 \\
\hline & 4. Fraca resposta dos consumidores quanto a novos produtos & 9,66 & 11,52 & 10,32 & 12,16 & 12,33 \\
\hline & 5. Escassez de serviços técnicos externos adequados & 11,52 & 15,90 & 15,28 & 24,40 & 15,14 \\
\hline \multirow[t]{3}{*}{ Organizacionais } & 6. $\quad$ Falta de pessoal qualificado & 23,93 & 22,10 & 36,11 & 49,52 & 32,18 \\
\hline & 7. Rigidez organizacional & 5,84 & 10,32 & 14,33 & 14,65 & 18,18 \\
\hline & $\begin{array}{l}\text { 8. Escassas possibilidades de cooperação com outras } \\
\text { empresas/instituições }\end{array}$ & 16,56 & 13,80 & 16,22 & 20,93 & 21,22 \\
\hline \multirow{3}{*}{$\begin{array}{l}\text { Técnicos e } \\
\text { tecnológicos }\end{array}$} & 9. Falta de informação sobre tecnologia & 15,23 & 12,07 & 13,89 & 16,14 & 16,65 \\
\hline & 10. Falta de informação sobre mercados & 12,66 & 9,92 & 8,99 & 13,46 & 13,19 \\
\hline & $\begin{array}{l}\text { 11. Dificuldade para se adequar a padrões, normas e } \\
\text { regulamentações }\end{array}$ & 17,73 & 18,69 & 14,03 & 19,53 & 19,76 \\
\hline
\end{tabular}

Fonte: Elaboração própria a partir dos dados da PINTEC/IBGE.

Nota-se que praticamente o mesmo resultado encontrado em relação às empresas industriais 'não inovadoras' é observado em relação às 'inovadoras'. Em outras palavras, tem-se que os 'riscos econômicos excessivos' e os 'elevados custos da inovação' são os principais obstáculos econômicos 
e institucionais apresentados, indiferentemente do porte da empresa inovadora. A 'escassez de fontes apropriadas de financiamento' também é apontada como obstáculo significativo pelas empresas inovadoras, porém as MPEs inovadoras são mais afetadas do que as demais. Finalmente, as empresas inovadoras também possuem uma percepção crescente de que a débil resposta dos consumidores no que se refere a novos produtos e a carência de serviços técnicos externos satisfatórios são obstáculos cada vez mais considerados.

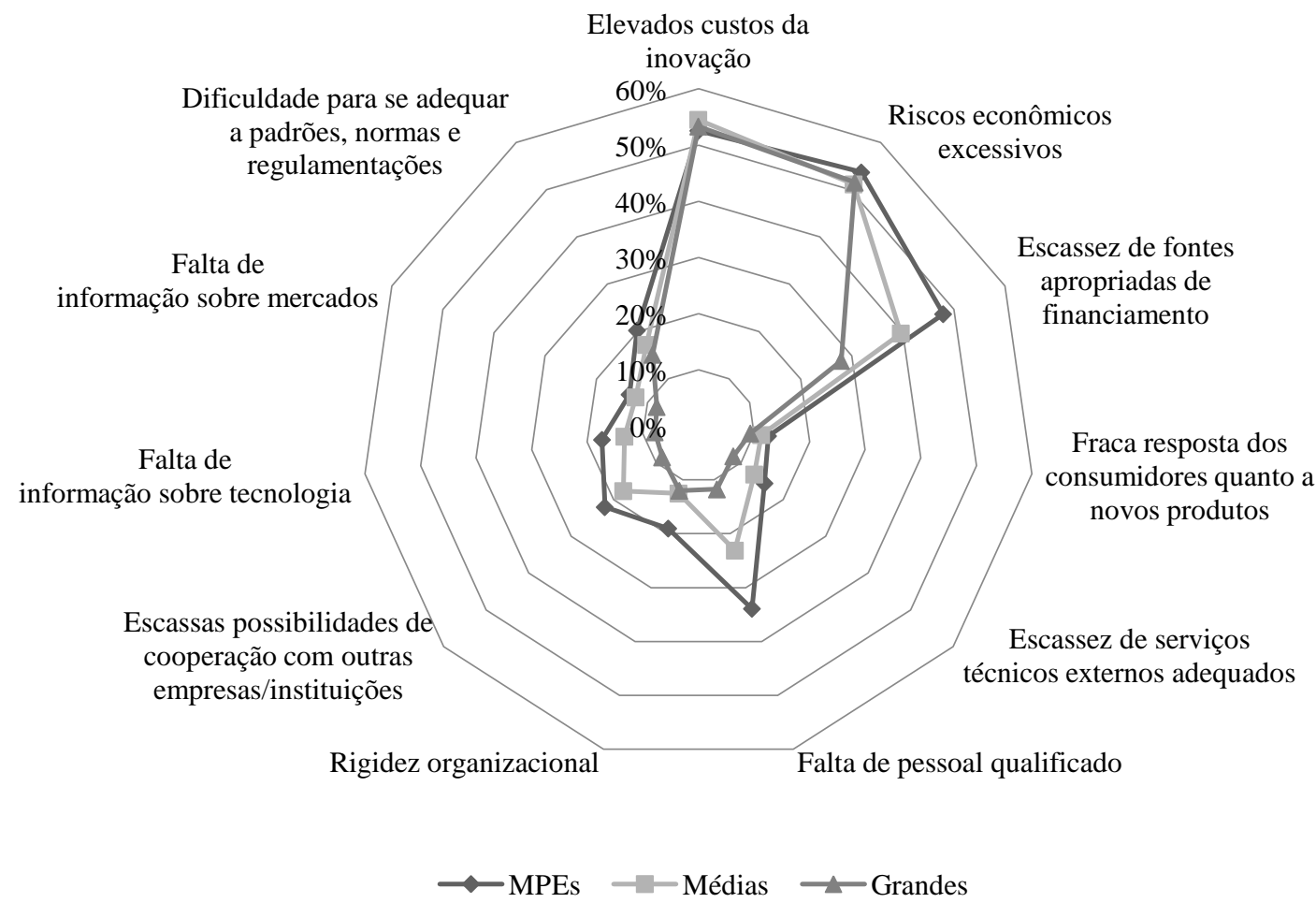

Figura 4 - Percentual do grau de importância 'alta' por obstáculos apontados pelas empresas industriais 'inovadoras' por porte, 2014

Fonte: Elaboração própria a partir dos dados da PINTEC/IBGE.

No que se refere aos obstáculos organizacionais, a 'falta de pessoal qualificado', a 'rigidez organizacional' e as 'escassas possibilidades de cooperação com outras empresas/instituições' têm sido apontadas pelas empresas industriais inovadoras como obstáculos de importância 'alta' à inovação, no entanto, são obstáculos mais significativos para as PMEs inovadoras do que para as médias e grandes empresas inovadoras.

Finalmente, no que se refere aos obstáculos técnicos e tecnológicos, as empresas industriais inovadoras têm praticamente a mesma percepção que as 'não inovadoras', pelo menos em 2014. Ademais, os obstáculos técnicos e tecnológicos são mais sensíveis às MPEs do que as médias e grandes inovadoras (Figura 4 e Tabela 7, anexo).

É possível concluir, portanto, que os fatores 'econômicos e institucionais', 'organizacionais' e 'técnicos e tecnológicos' afetam praticamente da mesma forma as empresas industriais inovadoras e as 'não-inovadores' e que as MPEs (inovadoras ou não) são mais afetadas por todos os fatores do que as grandes empresas. 


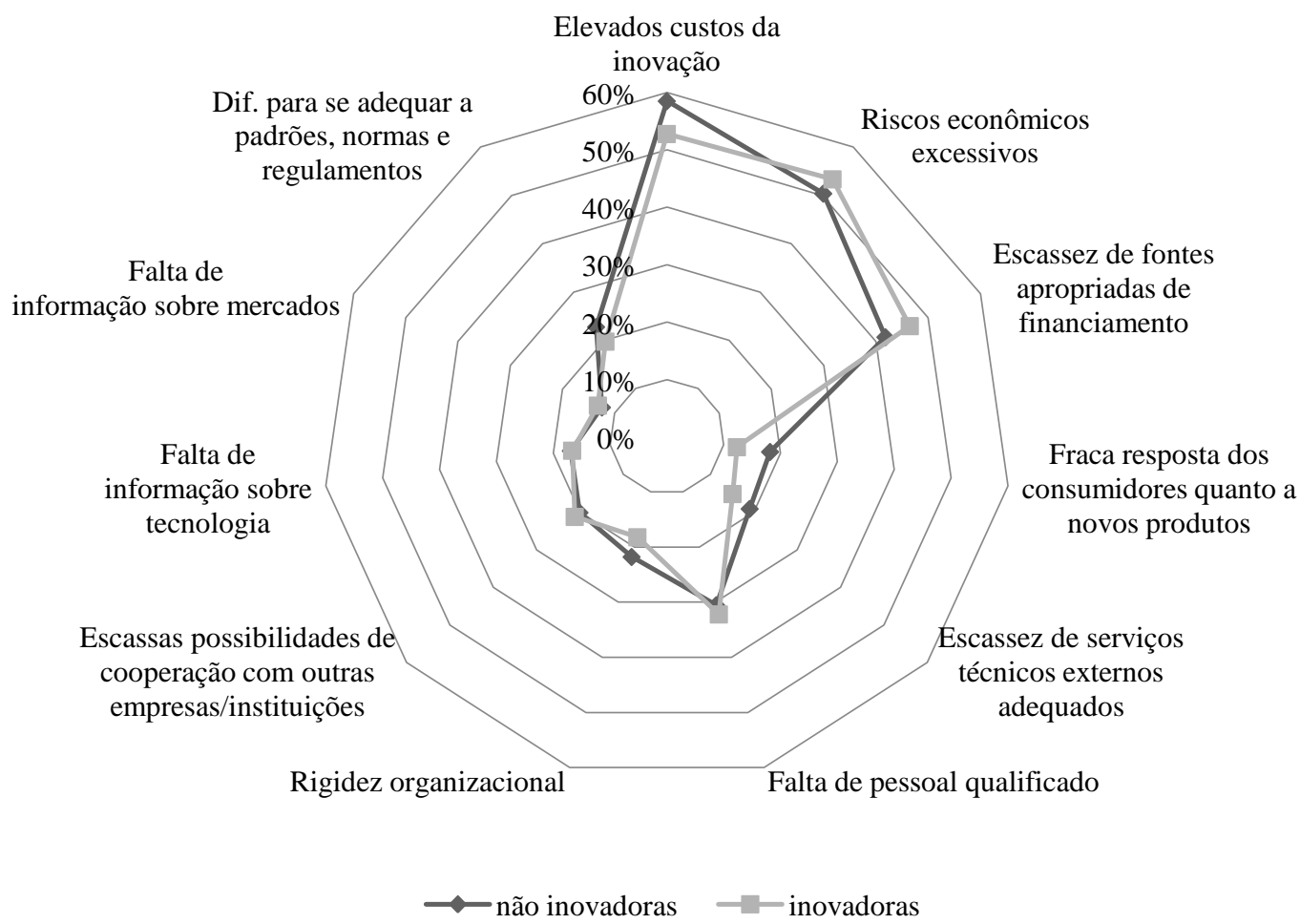

Figura 5 - Percentual do grau de importância 'alta' por obstáculos apontados pelas empresas industriais 'não inovadoras’ e empresa industriais inovadoras, 2014.

Fonte: Elaboração própria a partir dos dados da PINTEC/IBGE.

\section{Considerações finais}

Há um cenário estrutural do ponto de vista macroeconômico que desestimula investimentos em atividades inovativas no Brasil. De acordo com Cano (2012) e Carvalho (2018), a política de câmbio demasiadamente valorizado aliado a práticas de juros reais elevados, desincentivam o empresário capitalista a investir na economia industrial. . O cenário mais adverso é resultante tanto da queda da atividade econômica mundial devido à crise financeira (no final dos anos 2000), do processo de desindustrialização (iniciado na década de 1990), da conjugação de juros elevados e câmbio sobrevalorizado e da crise político-econômica (iniciada a partir de 2013). O Relatório da Fiesp (2010) aponta que a 'elevada taxa de juros' e a 'instabilidade/valorização do câmbio', itens que compõem a categoria 'riscos econômicos', são os principais fatores que impedem e dificultam os investimentos em atividades inovadoras. "As elevadas taxas de juros, contaminam o cálculo do custo de oportunidade dos projetos de investimento representando um incentivo aos investimentos não-produtivos (...) [e a valorização do câmbio dificulta] a conquista de mercados e prejudica as exportações de produtos de alto valor agregado" (FIESP, 2010, p.6)

Todo esse cenário impede (ou na melhor das hipóteses, dificulta) a expansão da população de empresas inovadoras no Brasil. De fato, o percentual de empresas industriais 'não inovadoras' mantém-se elevado e praticamente inalterado de 2003 a 2014 (63,98\% e 60,61\%), o que é significativo se recordado que a amostra da PINTEC é enviesada para empresas potenciais inovadoras. E o grupo de empresas industriais que possui o maior percentual de empresas "não inovadoras' é aquele formado pelas MPEs no período 2003-14. As grandes empresas industriais (acima de 500 funcionários empregados), por exemplo, que possuíam um percentual relativamente pequeno de empresas 'não inovadoras' em 2003 (24,56\%) aumentaram para 32,47\% (em 2014), conforme apresentado na Tabela 3 e o principal motivo impeditivo foi as 'condições adversas de mercado', no entanto, 'outros fatores impeditivos' foram apontados também pelas empresas 'não inovadoras' independente do seu porte.

Uma análise descritiva dos dados da PINTEC permitiu verificar que dentre os demais fatores impeditivos, os principais fazem parte de um conjunto de fatores de natureza 'econômica e 
institucional'. Para todos os portes de empresa 'não-inovadora', o principal desses obstáculos, para todos os anos analisados, é o 'elevado custo de inovação', seguido dos 'riscos econômicos' e da 'escassez de fontes apropriadas de financiamento'. Esses fatores mostram-se igualmente importante tanto para MPEs quanto para médias e grandes empresas.

Ademais, os dados permitiram afirmar que os 'obstáculos organizacionais' e os 'obstáculos tecnológicos' afetam de forma diferente no que tange o porte das empresas. Por exemplo, a 'falta de pessoal qualificado' (embora se apresente de forma crescente como obstáculos para as empresas 'não inovadoras' independente do porte), afeta mais as MPEs do que as grandes empresas. O mesmo pode ser dito da 'rigidez organizacional', das 'escassas possibilidades de cooperação com outras empresas', da 'falta de informação sobre tecnologia', da 'falta de informação sobre mercados' e da 'dificuldade para se adequar a padrões, normais e regulamentações'.

É bem verdade que vários instrumentos foram criados nos últimos anos para lidar com vários dos 'obstáculos organizacionais' e 'obstáculos tecnológicos' - Lei do Bem, Lei da Inovação, Lei de Incentivo à Pesquisa - no entanto, os problemas ainda persistem e as MPEs também se mantem como as mais afetadas. Ademais, as MPEs apresentam dificuldades em absorver a 'cultura da inovação' dentro de suas estruturas e dificilmente reconhecem os impactos positivos de programas de gestão tecnológica (Fiesp, 2010).

Finalmente, a análise descritiva dos dados permitiu constatar que as empresas inovadoras apontam as mesmas dificuldades do que as 'não inovadoras' para seus processos inovativos. Igualmente, ficou patente que o porte das empresas inovadoras afeta sua percepção quantos aos obstáculos enfrentados para levar a cabo seus novos produtos e processos.

Portanto, a análise proposta neste trabalho permitiu constatar que os obstáculos econômicos (e institucionais), tecnológicos e organizacionais são fatores que dificultam e impedem processos inovativos de forma semelhante em empresas 'inovadoras' e 'não inovadoras', no entanto, o porte da empresa (seja ela inovadora ou não) importa. Isso é, quanto maior o tamanho da empresa (cuja proxy é o número de empregados) menos obstáculos ela enfrenta para inovar vis-à-vis as MPEs e as médias. Os instrumentos e mecanismos de fomento à inovação, ainda que tenham se ampliado de forma considerável nas últimas décadas e que estejam sendo importantes para o fomento às MPEs (Avellar; Botelho, 2015), não fazem clara distinção entre empresas que já inovam e que deveriam aumentar seu esforço inovador, de empresas que ainda não inovam, mas que poderiam começar a inovar. Ainda que os obstáculos enfrentados por este conjunto distinto de empresas sejam semelhantes, as formas de superá-los sãos distintas, merecendo maior atenção por parte das instituições de fomento, como Finep, FAPs e BNDES.

Alguns trabalhos já evidenciaram que algumas empresas "aprendem" a captar recursos públicos (Cannan, 2016) e o fazem de forma sistemática ao longo dos anos, inclusive de distintas agências de fomento (Silva, et al. 2010). Portanto as restrições de financiamento para quem não inova, estão relacionadas à dificuldade em conseguir captar os recursos o que é distinto de restrições de financiamento para quem inova, que pode estar associado a recursos de diferentes modalidades ou de maior magnitude nas distintas etapas do processo de inovação.

Finalmente vale lembrar que inovar é uma atividade complexa e envolve uma multiplicidade de atores e interações. Esse processo pode ser afetado em diversas etapas por diferentes barreiras, algumas das quais podem ser insuperáveis e interrompem por completo o processo inovativo. Tais barreiras variam de acordo com o tipo de inovação, com os atores do sistema de inovação envolvidos, com o tipo de empresa, com o setor econômico ao qual a empresa se insere, com a localização da empresa e com o seu tamanho.

A análise descritiva dos dados proposta nesse artigo é a fase inicial de estudos que visam avançar o entendimento das relações entre portes de empresas e obstáculos enfrentados em seus processos inovativos. Estudos futuros poderiam abranger o tipo de inovação, o porte e os obstáculos ao processo de inovação, bem como as diferenças setoriais e o porte na percepção dos obstáculos à inovação (Zahler et al., 2018).

\section{Referências}


ACEMOGlu, D.; ROBInSON, J. Why Nations Fail: The Origins of Power, Prosperity and Poverty. New York: Crown Books, 2012.

ARTHUR, W. B.. The nature of technology: what it is and how it evolves. Nova Iorque: Free Press, 2009.

AVELlAR, A. P. M.; BOTELHO, M. R.. Políticas de apoio à inovação em pequenas empresas: evidências sobre a experiência brasileira recente. Economia e Sociedade, v. 24, n. 2, p. 379-417, 2015.

BASTOS, C.; REBOUÇAS, M.; BIVAR, W. A construção da Pesquisa Industrial de Inovação Tecnológica (PINTEC). In: VIOTTI, E. B. e MACEDO, M. D. M. (Ed.). Indicadores de ciência, tecnologia e inovação no Brasil. Campinas: Editora da UNICAMP, 2003.

BORRÁS, S.; EDQUIST, C. Education, training and skills in innovation policy. Science \& Public Policy, v. 42, n. 2, p. 215-227, 2015.

BOSWORTH, D. Barries to growth: the labour market. In: BARBER, J.;METCALFE, S., et al (Ed.). Barriers to Growth in Small Firms. New York: Routledge, 1989. cap. 4, p.5886.

BRASIL. Lei Complementar n.123 de 14 de dezembro. Institui o Estatuto Nacional da Microempresa e da Empresa de Pequeno Porte. Brasília, 2006. Disponível em: <http://www.planalto.gov.br/ccivil_03/LEIS/LCP/Lcp123.htm>, acesso em 24/09/2018.

CANAAN, R.G. Financiamento à inovação em Biotecnologia: uma avaliação da atuação da FINEP no aporte de recursos não-reembolsáveis. 2016. 104 f. Dissertação (Mestrado Profissional em inovação Biofarmacêutica). Universidade Federal de Minas Gerais. Belo Horizonte, 2016.

CANEPA, A.; STONEMAN, P. Financial constraints to innovation in the UK: evidence from CIS2 and CIS3. Oxford Economic Papers, v. 60, n. 4, p. 711-730, 2008.

CANO, W. A desindustrialização no Brasil. Economia \& Sociedade, v. 21, n. Número Especial, p. 831-851, 2012.

CARVALHO, L.. A valsa brasileira. São Paulo, São Paulo: Todavia Livros, 2018.

CAVALCANTE, L. R.; DE NEGRI, F. A Trajetória Recente dos Indicadores de Inovação no Brasil. Texto para Discussão TD1659. Brasília: Instituto de Pesquisa Econômica Aplicada (IPEA). 2011

CHANDLER JR, A. D. Scale and scope: the dynamics of industrial capitalism. Cambridge: The Belknap Press of Harvard University Press, 1990. 760p.

COAD, A.; PELlEGRINO, G.; SAVONA, M. Barriers to innovation and firm productivity. Economics of Innovation and New Technology, v. 25, n. 3, p. 321-334, 2016.

CONNER, K. R.; PRAHALAD, C. K. A Resource-Based Theory of the Firm: Knowledge Versus Opportunism. Organization Science, v. 7, n. 5, p. 477-501, 1996.

D'ESTE, P. et al. What hampers innovation? Revealed barriers versus deterring barriers. Research Policy, v. 41, p. 482-488, 2012.

ETZKOWITZ, H.; LEYDESDORFF, L.. The dynamics of innovation: from National Systems and "Mode 2" to a Triple Helix of university-industry-government relations. Research Policy, v. 29, p.109-123, 2000

FIESP. Obstáculos à Inovação. São Paulo: Departamento de Competitividade e Tecnologia (DECOMTEC) da Federação das Indústrias do Estado de São Paulo (FIESP). 2010

FREEL, M. S. Barriers to Product Innovation in Small Manufacturing Firms. International Small Business Journal, v. 18, n. 2, p. 60-80, 2000.

FURTADO, A.; QUEIROZ, S. A construção de indicadores de inovação. Revista Inovação UNIEMP, n. 2, p. 26-28, 2005.

HADJIMANOLIS, A. The Barriers Approach to Innovation. In: SHAVININA, L. V. (Ed.). The International Handbook on Innovation. Kidlington: Elsevier Science Ltd, 2003. p.559-573. 
HEWITT-DUNDAS, N. Resource and Capability Constraints to Innovation in Small and Large Plants. Small Business Economics, v. 26, p. 257-277, 2006.

IBGE, Instituto Brasileiro de Geografia e Estatística. Pesquisa de Inovação - PINTEC, 2011. Rio de Janeiro: Coordenação de Indústria, 2013. Disponível em: <ftp://ftp.ibge.gov.br/Industrias_Extrativas_e de_Transformacao/Pesquisa_de_Inovaca o_Tecnologica/2011/Pintec2011.pdf >, acesso em 24/09/2018.

IBGE, Instituto Brasileiro de Geografia e Estatística. Demografia das Empresas. Rio de Janeiro, 2012. Disponível em: 〈https://biblioteca.ibge.gov.br/visualizacao/livros/liv61536.pdf>, acesso em 24/09/2018.

KÜHL, M. R.; CUNHA, J. C. D. Obstacles to implementation of innovations in Brazil: how different companies perceive their importance. Brazilian Business Review, v. 10, n. 2, p. 1-24, 2013.

LUNDVALL, B.- $\AA$. National Systems of Innovation: Towards a theory of innovation and interactive learning. London: Pinter, 1992

LUNDVALL, B.- $\AA$.; JOHNSON, B. The Learning Economy. Journal of Industrial Studies, v. 1, n. 2, p. 23-42, 1994.

MAIA, M. D. M. A.; SILVA-FILHO, J. C. L. Obstáculos a inovação na indústria brasileira: uma análise setorial. Revista Tecnologia e Sociedade, v. 12, n. 26, p. 135-154, 2016.

MALERBA, F. Learning by firms and incremental technological change. The Economic Journal, v. 102, n. 413, p. 845-859, 1992.

MOHNEN, P.; ROSA, J. Les obstacles à l'innovation das les industries de services au Canada. Revue d'Analyse Économique, v. 77, n. 2, p. 231-254, 2001.

MOLINA-YCAZA, D.; SÁNCHEZ-RIOFRÍO, A. Obstáculos para la micro, pequeña y mediana empresa en América Latina. Pymes, Innovación y Desarrollo, v. 4, n. 2, p. 21-36, 2016.

NELSON, R. R. Why do firms differ and how does it matter. Strategic Management Journal, v. 12, p. 61-74, 1991.

NELSON, R. R.; WINTER, S. Uma teoria evolucionária da mudança econômica. Campinas (SP): Editora da UNICAMP, 2005 [1982]. 632p.

OLIVEIRA, C. E. D. Problemas e obstáculos para a realização de inovações em empresas brasileiras. Revista Brasileira de Gestão e Inovação, v. 3, n. 1, p. 93-112, 2015.

OLIVEIRA, V. P.; BERTONI, R. B. Problemas e obstáculos à inovação em pequenas e médias empresas no Brasil: uma discussão a partir da pesquisa de inovação - PINTEC. Revista Pymes, Innovación y Desarrollo, v. 2, n. 3, p. 4-29, 2014.

PELlEGRINO, G.; SAVONA, M. Is Money All? Financing Versus Knowledge and Demand Constraints to Innovation. Working Paper Series N. 2013-029. Maastricht : Maastricht Economic and social Research institute on Innovation and Technology (UNU- MERIT). 2013

PENROSE, E. A teoria do crescimento da firma. Campinas (SP): Editora UNICAMP, 2006. 398p.

PIATIER, A. Barriers to innovation. London: Frances Pinter Publishers Ltd., 1984. 260.

RAPINI, M. S. Padrão de financiamento aos investimentos em inovação no Brasil. Texto para Discussão n. 497. Belo Horizonte: Centro de Desenvolvimento e Planejamento Regional (Cedeplar) da Universidade Federal de Minas Gerais (UFMG). 2013

RAPINI, M. S.; CHIARINI, T.; BITTENCOURT, P. F. Obstacles to innovation in Brazil: The lack of qualified individuals to implement innovation and establish university-firm interactions. Industry and Higher Education, v. 31, n. 3, p. 168-183, 2017.

REBOUÇAS, M. Pintec: pequenas empresas mostram melhor desempenho. Entrevista concedida a Simone Pallone e Wanda Jorge. Inovação Uniemp, Campinas (SP), v. 1, n. 3, p. 6-9, 2005. 
REIS, E. A.; REIS, I. A.. Análise descritiva de dados. Relatório Técnico do Departamento de Estatística da UFMG. Disponível em: 〈http://www.est.ufmg.br/ > , acesso em $17 / 01 / 2019$.

ROTHWELL, R. Small firms, innovation and industrial change. . Small Business Economics, v. 1, n. 1, p. 51-64, 1989.

SEBRAE. Serviço Brasileiro de Apoio às Micro e Pequenas Empresas. Anuário do Trabalho na Micro e Pequena Empresa. Brasília: Departamento Intersindical de Estatística e Estudos Socieconômicos (DIEESE), 2013. Disponível em: <http://www.sebrae.com.br/Sebrae/Portal\%20Sebrae/Anexos/Anuario\%20do\%20Trabal ho\%20Na\%20Micro\%20e\%20Pequena\%20Empresa_2013.pdf $>$, acesso em 24/09/2018.

SCHUMPETER, J. A. Capitalism, socialism and democracy. New York: Harper Perennial Modern Thought, 2008 [1942]. 431p.

SILVA-FILHO, J. C. L.; BRAGA, C. S. C.; REBOUÇAS, S. M. D. P. Percepção de obstáculos à inovação na indústria brasileira de transformação International Journal of Innovation, v. 5, n. 1, p. 114-131, 2017.

SILVA, L,A. RAPINI, M.S. SCHULTZ, S. Instrumentos financeiros de apoio à inovação: como é a participação das empresas mineiras. Seminário sobre a Economia Mineira, Diamantina, 2010.

SILVA, D. R. M.; FURTADO, A. T.. Modelos teóricos e interesses de mensuração no surgimento da pesquisa e inovação brasileira (Pintec). Revista Brasileira de Inovação, v. 16, n. 1, p. 97-128, 2017.

TANG, H.-K.; YEO, K.-T. Innovation under Constraints: The Case of Singapore. In: SHAVININA, L. V. (Ed.). The International Handbook on Innovation. Kidlington: Elsevier Science Ltd, 2003. p.873-881.

ZAHLER, A.; GOYA, D.; CAAMAÑO, M. The role of obstacles to innovation on innovative activity: an empirical analysis. LALICS Conference. Ciudad de Mexico, 2018.

ZEVALLOS, E. . Micro, pequeñas y medianas empresas en América Latina. Revista de la Cepal, v. 79, p. 53-70, 2003. 


\section{ANEXO}

Tabela 6 - Distribuição percentual dos obstáculos de grau de importância 'alto' apontados pelas empresas industriais 'não inovadoras' que impedem o processo inovativo, segundo tamanho, 2003, 2005, 2008, 2011 e 2014.

\begin{tabular}{|c|c|c|c|c|c|c|c|c|c|c|c|c|c|c|c|}
\hline \multirow[b]{2}{*}{ Obstáculos } & \multicolumn{5}{|c|}{$\begin{array}{c}\text { Micro e pequenas empresas 'não } \\
\text { inovadoras' }\end{array}$} & \multicolumn{5}{|c|}{ Médias empresas 'não inovadoras' } & \multicolumn{5}{|c|}{ Grandes empresas 'não inovadoras' } \\
\hline & 2003 & 2005 & 2008 & 2011 & 2014 & 2003 & 2005 & 2008 & 2011 & 2014 & 2003 & 2005 & 2008 & 2011 & 2014 \\
\hline 1. Elevados custos da inovação & 71,56 & 67,24 & 58,33 & 56,53 & 58,45 & 63,21 & 60,63 & 54,03 & 50,50 & 59,47 & 43,69 & 54,43 & 52,31 & 53,12 & 57,81 \\
\hline 2. Riscos econômicos excessivos & 58,77 & 51,30 & 49,24 & 43,68 & 50,19 & 52,65 & 53,55 & 48,24 & 43,90 & 51,91 & 37,75 & 38,24 & 50,13 & 34,16 & 61,48 \\
\hline $\begin{array}{l}\text { 3. Escassez de fontes apropriadas de } \\
\text { financiamento }\end{array}$ & 46,04 & 51,28 & 39,99 & 38,75 & 42,08 & 39,54 & 41,84 & 34,03 & 31,50 & 38,19 & 34,77 & 39,79 & 41,11 & 30,52 & 40,39 \\
\hline $\begin{array}{l}\text { 4. Fraca resposta dos consumidores quanto a } \\
\text { novos produtos }\end{array}$ & 7,91 & 6,68 & 10,07 & 10,34 & 18,42 & 7,46 & 12,36 & 9,11 & 7,63 & 15,67 & 7,41 & 7,25 & 5,56 & 9,54 & 7,17 \\
\hline $\begin{array}{l}\text { 5. Escassez de serviços técnicos externos } \\
\text { adequados }\end{array}$ & 8,23 & 12,73 & 10,81 & 19,37 & 19,66 & 5,95 & 9,49 & 8,22 & 11,13 & 11,91 & - & 3,63 & 4,42 & 5,06 & 4,44 \\
\hline 6. Falta de pessoal qualificado & 18,98 & 15,69 & 19,69 & 41,79 & 31,48 & 13,56 & 13,05 & 17,84 & 28,42 & 17,13 & 3,47 & 3,63 & 11,07 & 17,14 & 13,40 \\
\hline 7. Rigidez organizacional & 6,60 & 6,27 & 6,47 & 13,55 & 22,54 & 2,54 & 6,77 & 10,44 & 10,92 & 11,31 & 5,27 & 10,88 & 7,80 & 13,42 & 5,15 \\
\hline $\begin{array}{l}\text { 8. Escassas possibilidades de cooperação com } \\
\text { outras empresas/instituições }\end{array}$ & 12,15 & 14,37 & 17,89 & 12,58 & 20,52 & 6,61 & 9,84 & 12,73 & 13,71 & 15,18 & 3,47 & 12,69 & 3,40 & 11,32 & 7,89 \\
\hline 9. Falta de informação sobre tecnologia & 9,14 & 11,47 & 8,68 & 13,70 & 17,53 & 3,79 & 1,53 & 8,21 & 11,30 & 8,02 & 3,47 & 1,83 & 2,24 & 6,35 & 3,17 \\
\hline 10. Falta de informação sobre mercados & 8,29 & 7,64 & 6,76 & 10,48 & 12,86 & 3,25 & 3,54 & 5,84 & 5,79 & 6,63 & - & 5,44 & 2,21 & 5,33 & 2,04 \\
\hline $\begin{array}{l}\text { 11. Dificuldade para se adequar a padrões, } \\
\text { normas e regulamentações }\end{array}$ & 16,15 & 16,23 & 13,06 & 15,99 & 23,40 & 4,83 & 5,02 & 11,60 & 13,40 & 14,88 & 1,74 & 9,07 & 3,31 & 10,02 & 6,31 \\
\hline $\begin{array}{l}\text { Total de empresas que não inovaram que } \\
\text { responderam às questões 'outros fatores' }\end{array}$ & 12.674 & 10.923 & 17.130 & 14.714 & 17.875 & & & & & & & & & & \\
\hline Total de micro e pequenas empresas & 12.021 & 10.342 & 16.172 & 13.669 & 16.733 & & & & & & & & & & \\
\hline Total de empresas médias & 595 & 526 & 867 & 882 & 973 & & & & & & & & & & \\
\hline Total de empresas grandes & 58 & 55 & 91 & 163 & 170 & & & & & & & & & & \\
\hline
\end{tabular}

Fonte: Elaboração própria a partir dos dados da PINTEC/IBGE. Nota: Micro e pequenas empresas = até 99 empregados; Média = de 100 a 499 empregados; Grande = acima de 500 empregados. 
Tabela 7 - Distribuição percentual dos obstáculos de grau de importância 'alto' apontados pelas empresas industriais inovadoras que dificultam o processo inovativo, segundo tamanho, 2003, 2005, 2008, 2011 e 2014.

\begin{tabular}{|c|c|c|c|c|c|c|c|c|c|c|c|c|c|c|c|}
\hline \multirow[b]{2}{*}{ Obstáculos } & \multicolumn{5}{|c|}{ Micro e pequenas empresas inovadoras } & \multicolumn{5}{|c|}{ Médias empresas inovadoras } & \multicolumn{5}{|c|}{ Grandes empresas inovadoras } \\
\hline & 2003 & 2005 & 2008 & 2011 & 2014 & 2003 & 2005 & 2008 & 2011 & 2014 & 2003 & 2005 & 2008 & 2011 & 2014 \\
\hline 1. Elevados custos da inovação & 55,45 & 56,54 & 48,12 & 52,08 & 52,56 & 52,77 & 48,11 & 43,03 & 48,95 & 54,51 & 47,35 & 43,86 & 38,13 & 46,12 & 53,31 \\
\hline 2. Riscos econômicos excessivos & 53,43 & 50,24 & 39,13 & 41,72 & 53,67 & 49,97 & 44,58 & 41,09 & 40,96 & 51,15 & 45,97 & 39,65 & 38,45 & 35,33 & 51,52 \\
\hline 3. Escassez de fontes apropriadas de financiamento & 47,51 & 48,94 & 39,90 & 43,59 & 47,93 & 38,97 & 39,59 & 30,04 & 31,16 & 39,65 & 27,44 & 26,88 & 19,01 & 23,65 & 27,93 \\
\hline $\begin{array}{l}\text { 4. Fraca resposta dos consumidores quanto a novos } \\
\text { produtos }\end{array}$ & 10,02 & 12,11 & 10,70 & 12,27 & 12,55 & 7,50 & 8,53 & 7,49 & 12,33 & 11,29 & 6,41 & 8,55 & 8,12 & 7,45 & 9,35 \\
\hline 5. Escassez de serviços técnicos externos adequados & 12,03 & 17,08 & 15,85 & 25,45 & 15,60 & 8,58 & 11,89 & 12,71 & 17,44 & 13,18 & 6,72 & 5,96 & 7,94 & 9,96 & 8,23 \\
\hline 6. Falta de pessoal qualificado & 24,98 & 23,16 & 37,99 & 51,42 & 33,90 & 19,77 & 17,77 & 25,22 & 36,83 & 23,11 & 9,58 & 14,66 & 18,01 & 23,75 & 11,76 \\
\hline 7. Rigidez organizacional & 5,61 & 10,51 & 15,12 & 14,47 & 19,02 & 6,98 & 9,18 & 8,52 & 17,37 & 12,52 & 8,21 & 9,71 & 9,57 & 11,80 & 12,01 \\
\hline $\begin{array}{l}\text { 8. Escassas possibilidades de cooperação com outras } \\
\text { empresas/instituições }\end{array}$ & 17,78 & 14,82 & 17,32 & 21,43 & 22,05 & 8,43 & 8,87 & 8,63 & 18,48 & 17,69 & 8,14 & 8,34 & 8,60 & 11,29 & 8,54 \\
\hline 9. Falta de informação sobre tecnologia & 16,09 & 12,92 & 14,49 & 16,25 & 17,33 & 10,52 & 8,14 & 10,55 & 16,07 & 13,30 & 6,71 & 7,05 & 7,60 & 12,45 & 7,84 \\
\hline 10. Falta de informação sobre mercados & 13,28 & 10,33 & 9,22 & 13,45 & 13,47 & 9,20 & 8,45 & 7,92 & 14,76 & 12,29 & 6,55 & 6,50 & 6,18 & 9,69 & 8,15 \\
\hline $\begin{array}{l}\text { 11. Dificuldade para se adequar a padrões, normas e } \\
\text { regulamentações }\end{array}$ & 18,54 & 19,82 & 14,39 & 20,10 & 20,21 & 13,62 & 14,12 & 11,50 & 15,05 & 17,17 & 8,77 & 10,71 & 11,51 & 14,05 & 15,08 \\
\hline $\begin{array}{l}\text { Total de empresas que inovaram que responderam às } \\
\text { questões sobre 'obstáculos à inovação' }\end{array}$ & 12.732 & 10.433 & 16.916 & 19.422 & 21.388 & & & & & & & & & & \\
\hline Total de micro e pequenas empresas & 11.097 & 8.698 & 14.788 & 17.325 & 18.671 & & & & & & & & & & \\
\hline Total de empresas médias & 1.167 & 1.181 & 1.508 & 1.618 & 2.059 & & & & & & & & & & \\
\hline Total de empresas grandes & 468 & 554 & 620 & 479 & 659 & & & & & & & & & & \\
\hline
\end{tabular}

Fonte: Elaboração própria a partir dos dados da PINTEC/IBGE. Nota: Micro e pequenas = até 99 empregados; Média = de 100 a 499 empregados; Grande = acima de 500 empregados. 